\title{
Nonformal education as health promotion method among European youth: the example of transitional Albania
}

Citation for published version (APA):

Tresa, E., Burazeri, G., Van den Broucke, S., Qirjako, G., \& Czabanowska, K. (2021). Nonformal education as health promotion method among European youth: the example of transitional Albania. Health Promotion International, 36(5), 1463-1472. https://doi.org/10.1093/heapro/daab005

Document status and date:

Published: 01/10/2021

DOI:

10.1093/heapro/daab005

Document Version:

Publisher's PDF, also known as Version of record

Document license:

Taverne

Please check the document version of this publication:

- A submitted manuscript is the version of the article upon submission and before peer-review. There can be important differences between the submitted version and the official published version of record.

People interested in the research are advised to contact the author for the final version of the publication, or visit the DOI to the publisher's website.

- The final author version and the galley proof are versions of the publication after peer review.

- The final published version features the final layout of the paper including the volume, issue and page numbers.

Link to publication

\footnotetext{
General rights rights.

- You may freely distribute the URL identifying the publication in the public portal. please follow below link for the End User Agreement:

www.umlib.nl/taverne-license

Take down policy

If you believe that this document breaches copyright please contact us at:

repository@maastrichtuniversity.nl

providing details and we will investigate your claim.
}

Copyright and moral rights for the publications made accessible in the public portal are retained by the authors and/or other copyright owners and it is a condition of accessing publications that users recognise and abide by the legal requirements associated with these

- Users may download and print one copy of any publication from the public portal for the purpose of private study or research.

- You may not further distribute the material or use it for any profit-making activity or commercial gain

If the publication is distributed under the terms of Article $25 \mathrm{fa}$ of the Dutch Copyright Act, indicated by the "Taverne" license above, 


\title{
Nonformal education as health promotion
} method among European youth: the example of transitional Albania

\author{
E. Tresa $\mathbb{D}^{1,2, *}$, G. Burazeri ${ }^{1,2}$, S. Van den Broucke ${ }^{3}$, G. Qirjako ${ }^{2,4}$, and \\ K. Czabanowska ${ }^{1,5}$
}

'Department of International Health, School CAPHRI, Care and Public Health Research Institute, Maastricht University, Maastricht, The Netherlands, ${ }^{2}$ Department of Public Health, Faculty of Medicine, University of Medicine Tirana, Tirana, Albania, ${ }^{3}$ Psychological Sciences Research Institute, Université Catholique de Louvain-la-Neuve, 1348 Ottignies-Louvain-la-Neuve, Belgium, ${ }^{4}$ Department of Health Promotions, Institute of Public Health, Tirana, Albania and ${ }^{5}$ Institute of Public Health, Faculty of Health Sciences, Jagiellonian University, Krakow, Poland

*Corresponding author: E-mail: eni_tresa@hotmail.com

\section{Summary}

Nonformal education methodology is promoted by the European Union as a priority. Western Balkan countries are supported in using this methodology via access Community funds (Erasmus + , previously Youth in Action). Nonformal education (proven as the most effective education method for youth) is expected to have the same impact if used in Public Health. We aimed to explore how nonformal education methodology contributes to health promotion through elaborating the example of transitional Albania. An Exploratory Sequential Mixed Methods design was used. We organized two focus groups: one with students of medical sciences and another with none medical students. We randomly selected eight participants per focus group from the Beyond Barriers association database (Contact point for Erasmus+ Programme in Albania). We used conventional content analysis to analyze qualitative data. Exploratory group interviews were conducted previously, using a questionnaire, which was piloted prior to administration. Of a population of 581 youth who participated in nonformal education activities during 2007-2013, 113 youths were interviewed. Ninety percent of interviewees declared that nonformal education activities have influenced improvement of their skills/competences or helped to acquire new ones; $53 \%$ declared that they reflected a change into personal behavior/ actions/attitudes. Trainees learned through practice. They intended to retain the healthy behavior even when the activity was finished. Nonformal education activities offered equal opportunities to all youth despite their gender or field of study. Nonformal education methodology is recommended to be used in health promotion campaigns targeting young people as a very effective tool.

Key words: non-formal education, health promotion, young people 


\section{INTRODUCTION}

The Europeanization process influences the Western Balkan (WB) countries as new member states and accession countries not only through norms and rules but also through new policies and programs (Denca, 2008). The European Union (EU) has supported the development of the EU youth policy and has influenced national youth policy through programs, such as Erasmus + (2014-2020) and Youth in Action (2007-2013) (Lejeune, 2015; European Commission, 2018). The formulation of European policy for NFE can be understood as a part of the 'Europeanization process in education' (Mikulec, 2015).

Nonformal education (NFE) is one of the methodologies promoted by the EU as a priority working area in the Council of Europe's youth field included in the agenda 2020 (Council of Europe and Committee of Ministers, 2003; Council of Europe and Youth, 2008; Witthaus et al., 2016). NFE is defined as 'an integral part of a lifelong learning concept that ensures that young people and adults acquire and maintain the skills, abilities and dispositions needed to adapt to a continuously changing environment' (Parliamentary Assembly and Committee on Culture and Education, 1999).

Health promotion (HP) is defined as 'the process of enabling people to increase control over, and to improve, their health' (World Health Organization, 2018). HP serves the core mission of higher education by supporting students and creating healthy learning environments, at colleges and universities (American College Health Association, 2020). The principles approach in HP include (i) a broad and positive health concept; (ii) participation and involvement; (iii) action and action competence; (iv) a settings perspective; and (v) equity in health (Grabowski et al., 2017). The principles approach in HP goes in the same line with the elements of NFE.

NFE influences in improvement of Public Health. It focuses on the positive elements of learning. NFE is used as well to promote health and improve psychophysical well-being among housewives and informal care workers in southern Spain. Through these activities, women empowerment is achieved by increasing self-esteem and self-confidence. Among NFE workshop participants there are evident positive effects on the cognitive and psychological dimensions (Pietilä, 2009). Participation and involvement are core principles of NFE. 'Learners are active participants in their learning, and that they and their families and communities are involved in running the nonformal education programme' (Kamala Achu et al., 2010).
Health Literacy is defined as 'people's knowledge, motivation and competences to access, understand, appraise, and apply health information in order to make judgments and take decisions in everyday life concerning healthcare, disease prevention and health promotion to maintain or improve quality of life during the life course' (Sørensen et al., 2012). NFE activities promote health literacy and well-being, leading to improvement of Public Health in the community context, where people live. Nonformal health education helps children and adolescents to acquire relevant information regarding their own health condition, share strategies to cope with the disease and with the physical and attitudinal barriers they face in their daily life, and develop a critical consciousness regarding their health rights and their role as citizens in a community (Pais et al., 2014).

NFE tries to empower the participants through building their competences and skills (Tudor, 2016). It is purposive but voluntary learning (Council of Europe and European Union, 2018). Inclusion and equity are the main pillars of NFE education (Kamala Achu et al., 2010). Comparing health of participants and nonparticipants in NFE activities seems that participation in NFE activities has a significant impact on relevant dimensions of the quality of life of children and adolescents with chronic disease. Participants do feel more satisfied with their health condition $[\mathrm{F}(1,160)=15.347, p<0.001]$, more capable of making decisions regarding their own health $[\mathrm{F}(1,160)=7.501, p=0.007]$ and to influence other people regarding issues related to chronic diseases $[\mathrm{F}(1,160)=37.003, p<0.001]$ (Pais et al., 2014). NFE activities give the possibility, especially to youngsters coming from disadvantaged groups, to act free from many of the constraints they experience in their daily lives, to experiment with aspects of their personality that are normally suppressed, and to a certain extent 'reinvent themselves' without fearing the disapproval of their peers (Friesenhahn et al., 2013). NFE activities provide opportunities to persons who often are hardly mobile in their daily lives to move to a neighboring town for further abroad education or employment opportunities (Kristensen, 2013).

NFE is used to train adults in many fields including health promotion in such countries as Australia, New Zealand, Korea, Japan, and the USA (Singh, 2015). Evaluation of NFE programs in Bangladesh showed they were effective and efficient (Ministry of Primary and Mass Education and Government of the Republic People's of Bangladesh, 2006). To reach a wide audience, NFE activities have been on air in national TV talking about nutrition, population control, maternity and childcare (Alamgir, 1999). Nonformal education is 
often seen as the most positive, efficient and attractive counterpart to educate young people (Monika Novosadova, Gulece Selen et al., 2006). It can be used for health-related issues as smoking, alcohol consumption, sport or gender (Singh, 2015).

In Albania, the prevalence of smoking among youth depends on gender and group age. Men smoke more than women. Of total, $12.3 \%$ of men $0.9 \%$ of women 15-19-year-old smoke. When age increases, the level of smoking also increases. In total, $44.1 \%$ of men and $5.9 \%$ of women $24-29$-year-old smoke. Of total $20 \%$ of girls and $31.1 \%$ of boys $15-19$ years old consume alcohol. Meanwhile, $35.2 \%$ of women 20-24-year-old consume alcohol and $67.9 \%$ of men 25-29-year-old. $82.7 \%$ of women do not exercise and $55.2 \%$ of them have a body mass index (BMI) over 25. Although $77.2 \%$ of men do not exercise, $59.8 \%$ of them have a BMI over 25 (Institute of Statistics and UNWOMEN, 2019).

The EU is linking NFE with a lifelong learning strategy (OECD, 2010). Even though NFE is promoted by the EU and a lot of money is invested in this field, there is no evidence for the use of NFE as a method for HP in the European Region, in WB and in Albania. No other study is available to give evidence of how NFE can be used as an HP method. Therefore, through this study, we aim to explore how NFE methodology contributes to HP to raise awareness among the youth thought the example of transitional Albania using a mixed-methods approach.

\section{METHODOLOGY}

The study is based on Exploratory Sequential Mixed Methods design (Creswell, 2014). This methodology allows exploration of the topic through a qualitative study in the first phase and then during the second phase to test or generalize the initial findings using quantitative methods (Berman, 2017). During a final phase, the data from the two separate strands of data are integrated and linked (Creswell and Clark, 2007).

The exploratory group interviews preceded a questionnaire study which was piloted prior to administration (Pope and Mays, 2006). Through quantitative methods, we tried to answer to the research question: How do participants of NFE activities perceive NFE methodology? Through qualitative methods, we asked their opinion on whether NFE methodology should be used in HP activities?

Through qualitative methods, we identified and built a theoretical background of NFE methodology whereas quantitative methods supported our findings with other data. All questions of both focus group discussion and survey are available in the Appendix.

\section{Qualitative methods}

Two focus group discussions (FGD) with eight participants each were organized. The participants were selected randomly from the Beyond Barriers Association (BBA) database. The inclusion criteria for the focus group were participants had to be young people 18-25 years old who had participated in at least one NFE activity. All interviewees were Albanian, and were volunteers in the BBA association. One of the FGD comprised eight students of medical sciences (three males and five females). In the other FGD, eight students of law, economics and engineering (four males and four females) participated. The division in the two FGD was based on the field of study and was conditional, to avoid any possible bias coming from previous knowledge on health promotion activities.

The main author of the study led the focus group based on pre-defined questions. There were ten questions in the FGD. They were related to the experience of the participants with NFE activities, their opinion on the methodology and if they see it as appropriate to be used in HP activities.

All the interviews were recorded. All data were transcribed and analyzed verbatim. Analysis was based on Conventional Content Analysis, 'coding categories are derived directly from the text data' (Hsieh et al., 2005) The results were compared with the same FGD and in between the FGDs.

\section{Quantitative methods}

We conducted a cross-sectional study based on a population of 581 volunteers of BBA. We collected data in 2013, a time when BBA was the contact point for Youth in Action Programme launched by the European Commission (2007-2013), now for the Erasmus + program (2014-2020). We contacted BBA, as at the time when the study was conducted, it was the only local NGO that worked with NFE and had an offline database of volunteers.

The sample was selected through systematic sampling methods and its size was calculated with a $95 \%$ confidence interval, a level of confidence $5 \%$ and a $10 \%$ population portion (London School of Hygiene and Tropical Medicine, 2009). We selected each five names in the BBA database, the first, the fifth, tenth, the fifteenth and so on. Of 112 minimal required sample, we interviewed 113 youngsters. The level of respondence was $95 \%$. As per operative definition, youngsters 
are considered students aged between 18 and 25 years old, volunteers of BBA. Youth in action Programme of the European Commission supported mobility of youngsters 13-30 years old (European Commission, 2013).

Inclusion criteria: Youngsters $18-25$ years old that had participated in at least one NFE activity and did not participate in the FGD and in validation of the questionnaire. From the BBA volunteer database, every fifth volunteer was contacted to participate in the study. We sent the questionnaire electronically to each of the selected candidates. Before that, we validated the questionnaire among other 16 participants/trainees/interviewees/volunteers (PTIV). Based on their feedback, some of the questions were re-formulated and adapted for clarity.

The questionnaire contained 23 closed questions about demographic data, such as age, gender, number of NFE activities they had participated and other questions about their experience with NFE activities. Questions were organized as per the five principles of HP (Grabowski et al., 2017). See Table 1 in the Appendix for the full pull of questions.

All data were analyzed with the Statistical Package for the Social Sciences) (SPSS, version 16) (IBM, 2020). Based on our dataset we were able to perform: descriptive analysis, and chi-square tests. The data we obtained allowed us to conduct all the needed analyses and to

Table 1: NFE activity methods and how knowledge is used

\begin{tabular}{lcc}
\hline Statement & Yes & No \\
\hline $\begin{array}{l}\text { During the NFE activity different work- } \\
\quad \text { ing methods were used }\end{array}$ & $100 \%$ & $0 \%$ \\
$\begin{array}{l}\text { I did not like the working methods } \\
\text { The methods used during the activity }\end{array}$ & $3.5 \%$ & $94.7 \%$ \\
$\quad$ were repetitive & $13.3 \%$ & $84.1 \%$ \\
$\begin{array}{l}\text { The working methods were in compli- } \\
\quad \text { ance with my way of learning }\end{array}$ & $92 \%$ & $7.1 \%$ \\
$\begin{array}{l}\text { Did you manage to memorize the infor- } \\
\quad \text { mation received during the activity? }\end{array}$ & $98.2 \%$ & $1.8 \%$ \\
$\begin{array}{l}\text { During the activity, I had space to reflect } \\
\text { on the topic }\end{array}$ & $95.6 \%$ & $4.4 \%$ \\
$\begin{array}{l}\text { During the activity, I discussed with other } \\
\text { participants }\end{array}$ & $93.8 \%$ & $4.4 \%$ \\
$\begin{array}{l}\text { After the activity, I shared experience and } \\
\quad \text { information with friends/family/other } \\
\quad \text { volunteers of the organization }\end{array}$ & $63.4 \%$ & $36.6 \%$ \\
$\begin{array}{l}\text { After the activity, I used the information } \\
\text { for presentations in/at school/work }\end{array}$ & $42.6 \%$ & $57.4 \%$ \\
$\begin{array}{l}\text { After the activity, I reflected on the activ- } \\
\text { ity in general }\end{array}$ & $91.2 \%$ & $8 \%$ \\
$\begin{array}{l}\text { After the activity was finished, I wanted } \\
\text { to take part in another one. }\end{array}$ & $97.3 \%$ & $1.8 \%$ \\
\hline
\end{tabular}

answer to our research objectives The chi-square test was used to analyze the independent proportions of categorical data (Mchugh, 2013). A value of $p \leq 0.05$ was considered statistically significant.

\section{Characteristics of the participants in the questionnaire}

The median age of interviewees was 22 years old (min 18 , max 25 , range 7 ). Of the total, $38 \%$ were male and $62 \%$ were female. The majority of the subjects studied medical sciences $(25 \%)$, social sciences $(23 \%)$, economics $(17 \%)$, engineering $(17 \%)$, law $(9 \%)$ and other subjects $12 \% .21 \%$ of interviewees participated for the first time in NFE activities from 2007 to 2010. The majority of them $(80 \%)$ participated for the first time in NFE activities from 2010 to 2013. The majority of interviewees $(80 \%)$ had taken part in $1-5$ activities. $17 \%$ had taken part in $6-10$ activities and only $4 \%$ had taken part in over 10 activities.

\section{RESULTS}

Based on the content analysis, the following categories were identified: Activity methods, Participation, Learning, Communication, Spirit, and Reflection Behavior. In some cases, subcategories were created: Learning methods, Communication/Learning (Fig. 1).

\section{Activity methods}

Different methods were used during the activity, in order to adapt to the different learning styles of the trainees. The Participants/Trainees/Interviewees/Volunteers (PTIV) thought that methods used during NFE activities were new and not known before. They found them as special methods of education. NFE methods were interactive methods of learning that keep trainees interested and focused. The information is served in a simple and

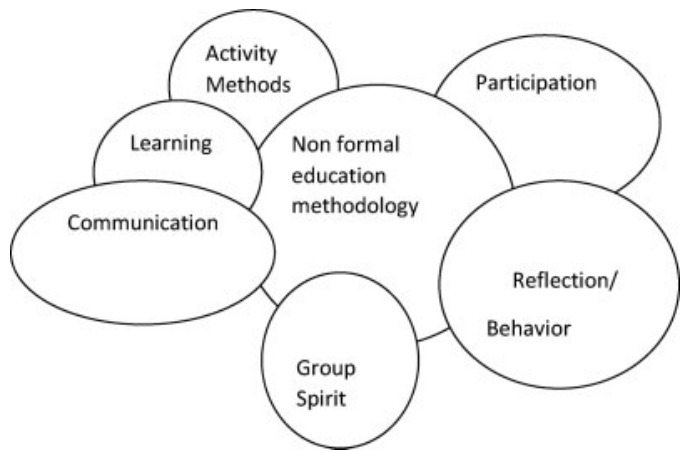

Fig. 1:Components of NFE methodology. Source: This study. 
understandable manner. Through concrete examples, PTIV were able to understand different situations and put the theoretical information into practice. All were presented in a new approach that youngsters like very much. In schools, they would lose concentration because of long PowerPoint presentations. In NFE activities, however, they were active all the time. NFE activities differ from traditional learning methods, as all activities are organized in working groups. During group work, they build the work based on each other ideas.

\section{Participation}

Participation in NFE activities was voluntary, not obligatory. The NGOs use techniques as 'mouth to mouth', presentations or innovative means of communication to promote NFE activities. PTIV said that they were influenced by their older siblings/friends to participate in NFE activities. Some of them had heard about NFE activities during presentations or open days at universities, NGO fairs in the city center, activities on Europe day. Social media was also a tool that informed PTIV about NFE activities. Through videos and photos, they were motivated to participate. NFE activities encourage the inclusion of people as people with disability/different ability can take part.

\section{Learning}

The process of learning was active. PTIV learnt through practice and there was no extended, long and boring theoretical information. They learnt through exchanging ideas, opinions and experiences with each other. Group was seen as resource. In this way, PTIVs increased their capacities and competences. PTIV described learning as 'was easy and interesting'. NFE activities fostered creativity and the desire to learn among participants. During the activity, PTIV met friends from other countries and this helped them to break down prejudices and stereotypes about other cultures. The activity fostered inter-culture dialogue.

\section{Learning methods}

Posters and leaflets may not be read as they require an active learning process. Through NFE, youngsters (PTIV) received the information passively through exercises and educational games. NFE activities used group work, open group discussions, reflections, role plays, simulation exercises, drama, small quizzes, case studies, outdoor group activities, brainstorms and videos to enhance learning process. Through debates and discussions, they learned to analyze different situations, to develop critical thinking and in the same time to be realistic and objective in the discussion. Through the methods used, PTIV could put themselves in the shoes of other people and see the situation with a different lens. The learning methods are appropriate for health education activities. The age range of participants in NFE activities allows the facilitator to create a smooth environment to discuss sensitive issues. Learning methods, such as peer-to-peer education, can be used to promote healthy behavior including sexual and reproductive health, sports, healthy diet, and road safety.

\section{Communication}

PTIV said that during NFE activities (different from formal education/school) they felt free to communicate, to express their opinion, without being afraid of the opinion of the professor. Even though the trainer/facilitator/ youth worker (TFYW) worked at the European level, they did not feel any barrier that would lead to difficulties in learning. Every idea was valid and there was no wrong answer. This made them free to express themselves leading to an increase of the self-confidence needed to take part in the discussion. Even though they did not know each other, there were organized 'getting to know each other' and 'icebreaker' activities that make them feel free to communicate.

\section{Communication/learning}

NFE activities helped PTIV to develop communication skills. They learned how to speak in public, communicate in small and big groups, and make presentations. PTIV developed their leadership skills. During youth exchanges, some of the participants were group leaders and this made them learn how to manage group dynamics, keep balance within groups and solve possible conflicts among group members. They learnt how to take decisions as a group even though they had different ideas at the beginning. Most of the PTIV developed their skills to communicate in a foreign language as in most of the cases, English was the main language of the activity. During the European Voluntary Service (EVS) volunteers could learn the local language through courses provided to them. They could also interact with local people, which helped them to learn how to behave, adapt and live in a new culture.

\section{Group spirit}

PTIV liked the general atmosphere of NFE activities. During NFE activity after 'getting to know each other' exercises, the entire group (including TFYW) worked with team building activities in order to create a warm environment for PTIV to feel safe to discuss and 
participate. The group spirit was in the same line with group dynamic and made NFE activities very effective in sharing the needed information to the disadvantaged groups.

\section{Reflection behavior}

NFE activities encouraged PTIV to reflect on their behavior. Discussion and working in groups all week long on health-related issues meant the PTIV intended to keep the healthy behavior even when the activity was finished. They tried to educate their family members and friends about healthy behavior. Not all changed their behavior. Some PTIV thought that they needed to take part in other activities and to follow up after the activity in order to use the information and to maintain their healthy behaviors. Working on health promotion, they intended to have healthy behavior themselves. The community benefited as well, by their increase of capacity. Some of the PTIV created other youth organizations that helped in the mobilization and learning of other youngsters in other disadvantaged areas.

\section{Results as per five principles of HP}

\section{A broad and positive health concept}

Around $70 \%$ of interviewees found NFE activities to be very interesting. None of them thought that NFE activities were somehow interesting or not interesting at all. Table 1 shows what the participants thought about the methods used in NFE activities and how the information received during the NFE activity was used. NFE is equally appreciated by both students of medical sciences and other students. There is no significant difference among those groups in the way they perceive NFE $(p=0.76)$ (Table 1$)$.

\section{Participation and involvement}

Of the total number of participants, $97 \%$ said that they worked well in the group and they felt free to open up and discuss with other participants (98\%). The majority of interviewees declared that they felt confident enough to have discussions on different topics. $95 \%$ of interviewees said that during the activity, an open environment was created to discuss sensitive health-related issues, such as sexual and reproductive health, physical activity, smoking, etc. Only $4 \%$ of the participants said the relationships with other participants were rigid and they could not discuss personal issues. After the activity, $63 \%$ shared what they learned with others like family members, friends, and other volunteers of the organization. No gender differences are present in this indicator $(p=0.93)$.
There was shown no significant difference in between medical students and other students in the way they participated in NFE activities $(p=0.42)$. In fact, there is no significant correlation in between the number of activities in which students participate and the perception they have about NFE activities $(p=0.81)$. As well as, there is no significant change in the number of activities in which medical students and other students have participated $(p=0.14)$.

\section{Action and action competence}

The majority of interviewees $(90 \%)$ declared that NFE activities had helped to improve their existing skills and competencies or to give them new ones. The majority of interviewees $(98 \%)$ said that they achieved to memorize the information received in NFE activities and $72 \%$ said they used the information received $(42 \%$ used for presentations in school). Around $80 \%$ of interviewees declared that they put into practice the information received and $53 \%$ declared that they reflected on changing the personal behavior/actions/attitudes. No evidence is available about the gender differences/field of study and influence of NFE activities in improving skills and competences (Table 2).

\section{A settings perspective}

$96 \%$ of participants declared that they themselves decided to take part in the activity and $4 \%$ said that they were influenced by friends. No gender influence is present in the participation in NFE activities $(p=0.40)$. $56 \%$ declared that they had heard of NFE activities before participation. Female participants significantly had more information about NFE activities before participation than males, $29 \%$ more $(p=0.003)$. Also, the information was shared with other colleagues or family members in $63 \%$ of the cases. There is no difference among male and female participants in the information they shared with family members $(p=0.936)$. Figure 2 shows the influence of NFE activities on participants. $98 \%$ of interviewees disagreed that the NFE activities did not have any influence on them.

\section{Equity in health}

Nonformal education activities offer equal information and possibility of training to both men and women, medical sciences students (who are supposed to have more information on public health issues) and other students. There is no significant difference among field of studies/gender and the valuable information they received for their lives. The values are, respectively, $p=0.91$ for field of study and $p=0.46$ for gender. 
Table 2: Disaggregation of data based on gender and Field of studies

\begin{tabular}{|c|c|c|c|c|}
\hline & \multicolumn{2}{|l|}{ Gender } & \multicolumn{2}{|c|}{ Field of study: medical/other } \\
\hline & Pearson chi-square & $p$-value & Pearson chi-square & $p$-value \\
\hline Influence of NFE activities in improving skills and competences & 1.8 & 0.407 & 0.443 & 0.506 \\
\hline Memorization of theoretical information received in NFE activity & 0.105 & 0.746 & 0.679 & 0.410 \\
\hline Use the information received & 4.218 & 0.121 & 1.912 & 0.384 \\
\hline Use the info for presentations in school & 1.08 & 0.299 & 3.114 & 0.078 \\
\hline Reflected to change the behavior/actions/attitudes & 0.563 & 0.453 & 1.029 & 0.310 \\
\hline Put into practice the theoretical information received & 0.167 & 0.683 & 0.488 & 0.485 \\
\hline Appreciation of NFE & & & 0.534 & 0.766 \\
\hline Share of information with family and friends & 0.006 & 0.936 & & \\
\hline Participation in NFE activities & 1.817 & 0.403 & 1.695 & 0.429 \\
\hline Information on NFE activities before participation & 9.13 & 0.003 & & \\
\hline Valuable information received for life & 0.546 & 0.460 & 0.013 & 0.911 \\
\hline Relation built with trainer & 2.344 & 0.310 & 2.032 & 0.362 \\
\hline Relation build with the group of participants & 1.582 & 0.208 & 0.336 & 0.562 \\
\hline
\end{tabular}

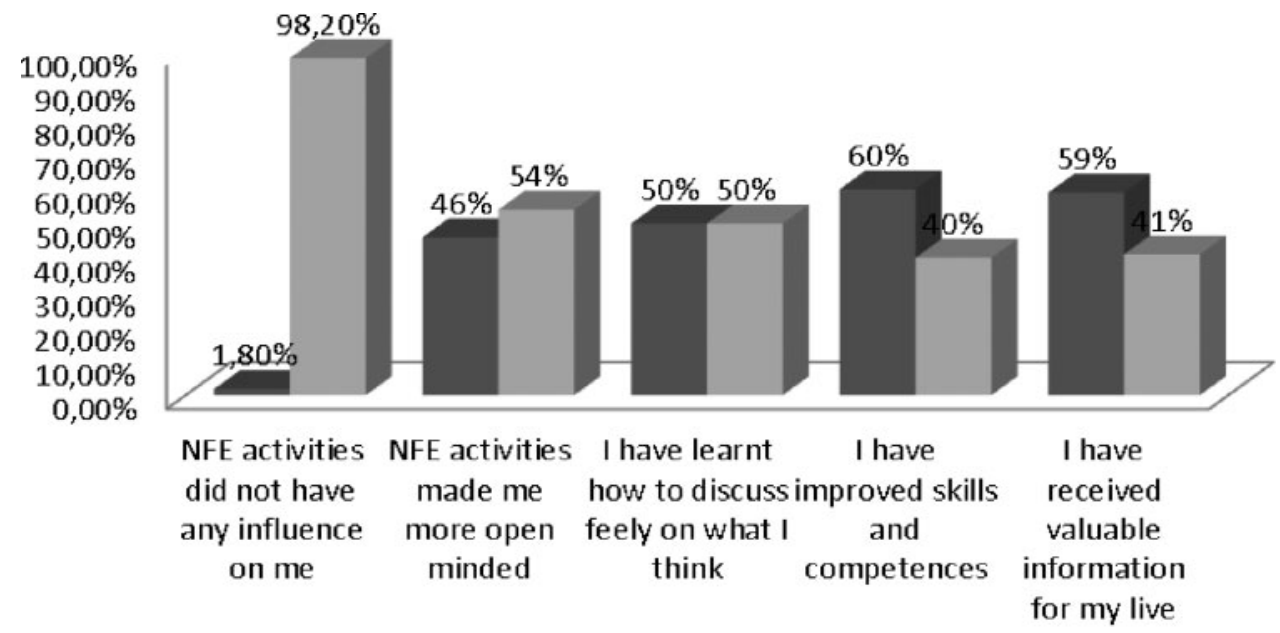

Yes No

Fig. 2:Influence of NFE activities.

About the relationship with the TFYW, 89\% of interviewees said they did not feel the presence of barriers; meanwhile, $11 \%$ said that even though they felt a distance, they could communicate. Only $1 \%$ said that there was a big barrier in between TFYW and participants and therefore they could not communicate freely. There is no significant difference of field of study/gender and the relation they build with TFYW. The test values are, respectively, $p=0.36$ for field of study and $p=0.31$ for gender. $99 \%$ of the PTIV say they had a friendly relation with the group of other PTIV which offered the space to communicate freely. No significant difference among medical students and other students/men and women is evident for this indicator. The scores are $p=0.56$ for field of study and $p=0.20$ for gender differences.

\section{DISCUSSION}

This study found that NFE activities are appropriate for young people. The results of this study support NFE methodology as an HP method that can be used during health education activities and health promotion campaigns. NFE activities are appropriate for all youth despite their fields of study, gender, or their places of origin. They offer equal opportunity to be informed about health activities, reflect about health-related issues 
and change their health behavior. Of the total, $53 \%$ of PTIV declared that the information and knowledge received in NFE activities, they used to reflect on change of personal behaviors/attitudes/actions and $63 \%$ had shared this information with friends, family members or other volunteers of the organization. $95 \%$ of interviewees said that during the activity an open environment was created to discuss on sensitive health-related issues, such as sexual and reproductive health, physical activity, smoking, etc. After the activity, $63 \%$ shared what they learned with others like family members, friends, and other volunteers of the organization.

Both qualitative and quantitative data showed that interviewees found NFE activities very interesting $(70 \%)$. The learning methods were very interactive and adapted to different learning styles. Group work was much appreciated as it made PTIV feel free to discuss with other participants (98\%). This led to confidence in discussing sensitive health issues like sexual and reproductive health or smoking. NFE activities helped PTIV to improve their skills and competences/acquire new ones $(90 \%)$. PTIV learnt to speak in public and develop leadership skills. PTIV learned through practice and NFE activities presented no extended, long and boring theoretical information.

Health promotion is a process of learning and 'enabling people to increase control over, and to improve, their health' (World Health Organization, 2018). NFE methodology goes in the same line with the five elements of the principles approach in HP:

1. $1 \mathrm{~A}$ broad and positive health concept

2. Participation and involvement

3. Action and action competence

4. A settings perspective

5. Equity in health (Grabowski et al., 2017)

NFE activities give young people new information in the way that they would like to listen to it, improve their skills and competences, and reflect on their behavior which leads to improving their health (Tudor, 2016). NFE activities give youngsters a positive prospective in learning process. They foster participation of youngsters with fewer opportunities and vulnerable groups to be active in their learning process (Kamala Achu et al., 2010). Health literacy is offered to young people in their contextual setting at community level (Pais et al., 2014). Since 90s NFE has been suggested as a method for health education in India especially reaching people living in slums, regarding malnutrition, infant mortality, sanitation-related disease and common disease (Selva et al., 1990). Nonformal education enables people to control situations that affect their lives. It gives equal opportunities to all youth without fearing the disapproval of their peers (Friesenhahn et al., 2013). The education approach in health promotion explains the importance of receiving information and developing skills to be able to make informed health choices. However, the changes in health behavior are voluntary (Qirjako et al., 2008). NFE activities allies with the education approach in health promotion.

NFE activities are oriented to the learning cycle of the participants. They aim to balance out the skills, theory and attitudes. Changing the attitudes of PTIV might lead to change of their habits. The KASH model explains the process of receiving theoretical information, practical skills and changes in attitudes aiming at changing habits (Neale et al., 2009). For this reason, methods of NFE have been used in India since 1993 to train school children 7-10years old on health nutrition including importance of nutrition, the major nutrients, and their food sources. Children that participated in these activities were compared with other children that did not participated. It was proven as an effective, lowcost methodology in learning (Udipi et al., 1993). NFE is also used in training manuals for people living with HIV (Alexandria and Bundy, 2004). NFE activities are used in countries like Australia, New Zealand, Korea, Japan, USA as HP methods among youngsters (Singh, 2015). As well, it was used to 'ever HIV tested young people among sexually active ones in Urban Chiang Mai, Thailand. It resulted that among sexually active youngsters, $65.4 \%$ did not consistently use condom' (Musumari et al., 2016).

Limitations of the study: This study was conducted in 2013, a time when the Youth in Action program had ended and contained only Albanian participants' data in NFE activities. Another data collection needs to be carried out in 2020 upon the completion of the Erasmus + program. The study will be more complete if it is conducted in many European countries or in the entire WB region. The quantitative study design did not allow us to have causal data analysis. However, the Exploratory Sequential Mixed Methods design gave us a broad prospective as to why NFE methodology should be used in $\mathrm{HP}$ activities.

In conclusion, NFE is a very effective tool in health promotion campaigns targeting youngsters. NFE activities help young people to reflect on their behavior. Youngsters like it very much as an HP method. The EU has put a lot of money in place and WB countries should use it to build HP activities. NFE methodology should be promoted as a health promotion tool among organizations/institution in WB countries that work in the 
health field. Manuals and booklets with best practices should be published containing step by step descriptions of how to use NFE methodology in the health field.

\section{ACKNOWLEDGMENTS}

We acknowledge Beyond Barriers Association and its Executive Director Ana Mullanji, for giving as access in their volunteer database. As well, we acknowledge Andrée Rose Catalfamo for her contribution in proof-reading.

\section{REFERENCES}

Alamgir, A. K. (1999) Nonformal education programmes in Bangladesh: A first step for developing. In PAN Commonwealth Forum on Open Learning. Darussalam. https://www.researchgate.net/publication/200779056_ Non-formal_education_programmes_in_Bangladesh_A_ first_step_for_developing (last accessed 5 February 2021).

Alexandria, V. and Bundy, D. (eds) (2004) Education and HIV/AIDS: A Source Book of HIV/AIDS Prevention Programs. Washington DC: The World Bank.

American College Health Association (2020) Health Education/Health Promotion. https://www.acha.org/ ACHA/Resources/Topics/Health_Promotion.aspx (last accessed 31 August 2020).

Berman, E. A. (2017) An exploratory sequential mixed methods approach to understanding researchers' data management practices at UVM: integrated findings to develop research data services. Journal of eScience and Librarianship, 6, 1-22. doi:10.7191/jeslib.2017.1104.

Council of Europe and Youth (2008) The Future of the Council of Europe Youth Policy: AGENDA 2020. Kyiv.

Council of Europe and Committee of Ministers (2003) Recommendation Rec(2003)8 of the Committee of Ministers to Member States on the Promotion and Recognition of Nonformal Education/Learning of Young People. Strasbourg: Council of Europe Publishing.

Council of Europe and European Union (2018) Nonformal Learning / Education. Brussels

Creswell, J. et al., (2014) Research Design: Qualitative, Quantitative, and Mixed Methods Approaches. 4th ed. Edited by B. Bauhaus Thousand Oaks, CA: Sage.

Creswell, J. and Clark, V. P. (2007) Choosing a Mixed Methods Design, Designing and Conducting Mixed Methods Research. Ch. 3. http://scholar.google.com/scholar?hl=en\& btnG $=$ Search\&q=intitle:Choosing $+\mathrm{a}+$ mixed + methods + design\#0 (last accessed 5 February 2021).

Denca, S. S. (2008) The impact of the European Union on foreign policy-making in Hungary, Romania and Slovakia: institutional adaptation, learning and socialization. Political Prospectives, 2, 1-35.

European Commission (2013) Youth in Action Programme Guide. http://ec.europa.eu/assets/eac/youth/tools/documents/ guide13_en.pdf (last accessed 10 July 2019).
Friesenhahn, G. J. et al. (eds) (2013) Learning Mobility and NonFormal Learning in European Contexts Policies, Approaches and Examples. Strasbourg: Council of Europe Publishing.

Grabowski, D. et al. (2017) Principled promotion of health: implementing five research-based prevention and management of diabetes. Societies, 1-15. doi: 10.3390/soc7020010.

Hsieh, H., Shannon, S. E. and Shannon, S. E. (2005) Three approaches to qualitative content analysis. Qualitative Health Research, 15, 1277-1288. doi: 10.1177/1049732305276687.

IBM (2020) Why IBM SPSS Statistics? https://www.ibm.com/uken/products/spss-statistics (last accessed 31 August 2020).

Institute of Statistics and UNWOMEN (2019) Women and Men in Albania. Tirana, Albania. http://www.instat.gov.al/me dia/6413/burra-dhe-gra_2019.pdf.(last accessed 5 February 2021)

Kamala Achu et al. (2010) Community-Based Rehabilitation: CBR Guidelines. Edited by C. Khasnabis and K. H. Motsch. Geneva: WHO Press. https://www.ncbi.nlm.nih.gov/books/ NBK310940/. (last accessed 5 February 2021)

Kristensen, S. et al., (2013) Mobility as a pedagogical tool for young people with fewer opportunities. In J G., Friesenhahn (eds), Learning Mobility and NonFormal Learning in European Contexts Policies, Approaches and Examples. Strasbourg: Council of Europe Publishing.

London School of Hygiene and Tropical Medicine (2009) The use of epidemiological tools in conflict-affected populations: open-access educational resources for policy-makers. http:// conflict.lshtm.ac.uk/page_35.htm (last accessed 13 September 2020).

Mchugh, M. L. (2013) The chi-square test of independence Lessons in biostatistics. Biochemia Medica, 23, 143-149. doi: 10.11613/BM.2013.018.

Mikulec, B. (2015) Validation of nonformal and informal learning from a European perspective - linking validation arrangements with national qualifications frameworks. Andragoška Spoznanja, 21, 7-19.

Ministry of Primary and Mass Education and Government of the Republic People's of Bangladesh (2006) NonFormal Education (NFE) Policy. Bangladesh

Musumari, P. M., Tangmunkongvorakul, A., Srithanaviboonchai, K., Yungyuankul, S., Techasrivichien, T., Suguimoto, S. P. et al. (2016) Prevalence and correlates of HIV testing among young people enrolled in nonformal education centers in urban Chiang Mai, Thailand: a cross-sectional study. PLoS One, 11, e0153452. doi: 10.1371/journal.pone.0153452.

Neale, S., Spencer-Arnell, L. and Wilson, L. (2009) Emotional Intelligence Coaching. Improving Performancee for Leaders, Coaches and the Individual. London: Spencer-Amel. doi:978 0749463564 .

Novosadova, M., Gulece Selen, A. P. et al. (2006). The Impact of Non Formal Education on Young People and Society. Edited by M. Nomikou. Brussels: AegeeEurope.

OECD (2010) Recognising NonFormal and Informal Learning: Outcomes, Policies and Practices. Paris. http://www.oecd. org/education/innovation-education/recognisingnonforma 
landinformallearningoutcomespoliciesandpractices.htm\#3 (last accessed 5 February 2021).

Pais, S. C., Rodrigues, M. and Menezes, I. (2014) Community as locus for health formal and nonformal education: the significance of ecological and collaborative research for promoting health literacy. Frontiers in Public Health, 2, 1-9. doi: 10.3389/fpubh.2014.00283.

Parliamentary Assembly and Committee on Culture and Education (1999) Doc. 8595, Non Formal Education. Brussels

Pietilä, P. (2009) A space of our own nonformal education for elder women in Andalusia. European Journal of Women's Studies, 16, 53-66. doi: 10.1177/1350506808098534.

Pope, C. and Mays, N. (eds) (2006) Qualitative Research in Health Care. 3rd ed. BMJ Books.

Qirjako, G., Roshi, E. and Burazeri, G. (2008) Promocioni Shendetesor. Shqiperia e Re, Tirana, Albania.

Selva, P., Sundararaj, P. and Surendra Kumar, P. (1990) Ancient science of life, Ancient Science of Life, 32-35. https://www. ncbi.nlm.nih.gov/pmc/articles/PMC3331260/pdf/ASL-1032.pdf (last accessed 5 February 2021).

Singh, M. (2015) Global Perspectives on Recognising NonFormal and Informal Learning: Why Recognition
Matters, Technical and Vocational Education and Training: Issues, Concerns and Prospects. Hamburg: Springer Open. doi: 10.1007/s11159-016-9534-0.

Sørensen, K., Van den Broucke, S., Fullam, J., Doyle, G., Pelikan, J., Slonska, Z. (HLS-EU) Consortium Health Literacy Project European. et al. (2012) Health literacy and public health: a systematic review and integration of definitions and models. BMC Public Health, 12, 80. doi: 10.1186/1471-2458-12-80.

Tudor, S. L. (2016) The role of nonformal and informal education in competences training - Transversal competences. In 8th International Conference on Electronics, Computers and Artificial Intelligence (ECAI). Ploiesti, Romania, pp. 1-6.

Udipi, S., Kamath, R. and Shah, N. (1993) Nutrition education of school children: a nonformal approach. Indian Journal of Maternal and Child Health, 4, 50-51.

Witthaus, G. et al. (2016) Validation of nonformal MOOC-based learning. In An Analysis of Assessment and Recognition Practices in Europe. European Union publication, Brussels. doi:10.2791/809371.

World Health Organization (2018) Health Promotion. Copenhagen. 